This is an electronic reprint of the original article. This reprint may differ from the original in pagination and typographic detail.

Author(s): Länsiluoto, Aapo; Järvenpää, Marko

Title: $\quad$ Collective action in implementation of a "greener" performance management system.

Year: $\quad 2010$

Version:

Please cite the original version:

Länsiluoto, A., \& Järvenpää, M. (2010). Collective action in implementation of a "greener" performance management system.. Journal of Accounting \& Organizational Change, 6(2), 200-227.

All material supplied via JYX is protected by copyright and other intellectual property rights, and duplication or sale of all or part of any of the repository collections is not permitted, except that material may be duplicated by you for your research use or educational purposes in electronic or print form. You must obtain permission for any other use. Electronic or print copies may not be offered, whether for sale or otherwise to anyone who is not an authorised user. 


\title{
Collective action in implementation of a "greener" performance measurement system
}

\author{
Aapo Länsiluoto (corresponding author) \\ University of Vaasa \\ Faculty of Business Studies \\ P.O.Box 700 \\ FIN 65101 VAASA \\ tel. +358 63248268 (office), +35840 5550776 (mobile) \\ fax +35863248344 \\ aapo.lansiluoto@uwasa.fi \\ Marko Järvenpää \\ University of Jyväskylä \\ School of Business and Economics \\ PO Box 35 \\ FIN 40014 Jyväskylän yliopisto \\ marko.jarvenpaa@econ.jyu.fi
}

Purpose; This study investigates how different actors affected the implementation of environmental management system (EMS) and performance management system (PMS) in a case company when EMS and PMS were finally integrated. Another purpose is to illustrate how the frameworks of Gibson and Earley (2007) and Lovaglia et al. (2003) can be utilized for investigating the implementation of different management systems in practice.

Methodology; This study is an interpretative case study, which utilizes qualitative methods such as semi-structured interviews and internal documents.

Findings; The results indicate the importance of separation between the power and status of an actor in EMS and PMS implementation processes. The power and status of actors in EMS and PMS implementation differed. The status and role of actor can change although the power can be static during the implementation of different management systems. Therefore, study confirms the classification of Lovaglia et al. (2003) and proposes that their classification should be added in the framework of Gibson and Earley (2007).

Practical implications; It is important to select the key actors and evaluate their power and status in the implementation of management systems deliberately. The implementation of management systems may be affected by both internal and external actors of organization.

Originality; Earlier accounting studies with institutional theory framework of Burns and Scapens (2000) have not specifically investigated the role of actors, their power and status in implementing 
two different management systems. Collective action frameworks of Gibson and Earley (2007) and Lovaglia et al. (2003) has not practically utilized before in EMS and PMS studies. Furthermore, the EMS and PMS integration studies have usually been normative without empirical case data.

Key words; collective action, implementation, integration, management systems, status, power Type of paper; Case study 


\section{Introduction}

Environmental management issues have been considered more and more both in public and private companies in recent years (Lozano and Vallés, 2007). Several reasons can motivate different organizations to consider environmental issues such as the improvement of image, profitability, amount of emissions or customer satisfaction (Darnall, 2006; Melnyk et al., 2003). Organizations are also able to utilize several different practical systems to conduct environmental actions. These environmental management systems (EMS) can be for instance different certifications such as ISO 14000 or different reporting frameworks such as Global reporting initiative (GRI).

In addition to increased interest in environmental issues, there has been a great amount of interest in general performance measurement systems (PMS) (e.g. Baxter and Chua, 2003; Kaplan and Norton, 2005; Lukka, 2007; Malmi, 2001; Tsamenyi et al., 2006). Organizations have several different PMS options to be utilized in practice such as the balanced scorecard (BSC) of Kaplan and Norton (2005), Tableu de board (Bourguignon et al., 2004), performance pyramids (e.g. Murdoch 1997), performance prism (Neely et al., 2002), the intangible asset scorecard (O'Connor and Feng, 2005), and the European Foundation for Quality Management (EFQM) Excellence Model (Jacobs and Suckling, 2007). The purpose of these PM systems is to help both monitoring and setting different targets for organizations. These PMS can be used also as an information system (Malmi, 2001). The PMS can provide both financial and non-financial information for decision making.

Although both PMS and EMS has received an attention separately, only some studies have considered the integration of PMS and EMS (Dias-Sardinha and Reijnders, 2005; Chung and Parker, 2008; Epstein and Wisner, 2001; Figge et al., 2002; Hubbard, 2008; Magrini and Lins, 2007; Pedersen and Neergaard, 2008; Yongvanich and Guthrie, 2006; Wagner 2007). This integration of PMS and EMS can benefit organizations in different ways. First, integration enables decision makers to get both environmental and performance related information from one system. Secondly, the integration can improve user satisfaction because users have to learn only the use of one integrated system. Thirdly, the updating of one system can be easier than multiple systems. Fourthly, the use of one system (for instance PMS) may increase also the utilization of another system (PMS). This study focuses on the implementation of EMS and PMS which were finally integrated as a one greener PMS in studied case organization. The PMS becomes 'a greener' when environmental measures are added into existing PMS (see for instance Figge et al., 2002).

Earlier EMS and PMS integration studies have some limitations from the point of view of this study. Some of these studies are normative without empirical data. These studies illustrate norma- 
tively different alternatives to integrate sustainability into a BSC (Epstein and Wisner, 2001; Figge et al., 2002; Hubbard, 2008) or PMS in general (Chung and Parker, 2008; Yongvanich and Guthrie, 2006). Some earlier studies have used survey method (Wagner, 2007) or quantitative case data (Magrini and Lins, 2007). On the other hand, Dias-Sardinha and Reijnders (2005) does have qualitative empirical data but their study assumes that PMS have been used only for managing environmental and social issues although there exist also other competing objectives such as quality, customer satisfaction. Due to these limitations of earlier studies, more EMS and PMS integration research which uses qualitative empirical data and assumes that environmental objectives are objectives among other objectives is needed. This study seeks to contribute to this above mentioned research gap in qualitative empirical research on EMS and PMS integration.

In addition to increased attention on EMS and PMS issues, the institutional theory has been used for describing the change process in different management accounting or management accounting information system studies (e.g. Baxter and Chua, 2003; Granlund, 2001; Soin et al., 2002; Tsamenyi et al., 2006). One of the most popular framework which uses institutional theory is presented by Burns and Scapens (2000). This framework of Burns and Scapens (2000) has been utilized in several different studies in recent decades (e.g. Guerreiro et al., 2006; Lukka, 2007; Nor-Aziah and Scapens, 2007; Soin et al., 2002). Despite the high utilization of framework of Burns and Scapens (2000), it has also some limitations, like all frameworks. This framework does not specifically consider the role of different actors during the change process (Pihlanto, 2000). The actor is a person who somehow, more or less, has affected on implementation managerial systems. The role of actors and different human factors may however be important when companies are changing or planning to change their PMS (see for instance Adams and Larrinaga-González, 2007; Ball, 2007; Burns, 2000; Pihlanto, 2000; Granlund, 2001; Hargrave and Van De Ven, 2006; Nor-Aziah and Scapens, 2007). Furthermore, for instance Lounsbury (2008 see also Ball, 2007) explicitly recommends conducting more studies which investigates how the collective action of actors affects management control systems in practice. Lounsbury (2008) even concludes that "much more needs to be done where logics and new practices come from and how they relate to each other". Also Ball (2007) concludes by recommending further investigation which especially focuses on the managers in private sector in the context of environmental issues.

Collective action theory can be seen as a modification of institutional theory (look, e.g. Hargrave and Van de Ven, 2006). Some studies informed by collective action theory specifically investigate the group and the actors of group effect on group performance. Some of these studies have conceptually developed different collective action frameworks and models without empirical data (e.g. 
Gibson and Earley, 2007; Lovaglia et al., 2003; Tang, 2008). Hence, there exist only some empirical studies which have applied collective action theory to investigate different phenomenon such as e-government development (Chou et al., 2008), IS standardization (Markus et al., 2006), network action in change process (Vogel, 2005) and top management team diversity (Jarzabkowski and Searle, 2004). However, we did not find any empirical studies which applies collective action theory in the field of PMS and EMS implementation. Therefore, collective action theory was considered an interesting and novel theoretical approach for the purposes of the study.

As earlier paragraphs described, we consider that there is a need for empirical study which utilizes collective action theory in the field of PMS and EMS implementation. This kind of study which analyzes where new management control systems and logics come from, how they relate to each others and what is the role of collective action is recommended also by Lounsbury (20008). In addition to Lounsbury (2008), Adams and Larrinaga-González (2007) legitimize the purpose of our study when they state “...environmental accounting literature has paid very little attention to either organizational influences on its practice, nor the impact of the practice of social and environmental accounting on organizations and their participants" Therefore, the primary purpose of this study is to investigate how different actors in a group affected the implementation of EMS and PMS in a case company. These two systems were finally integrated as one greener PMS. Another purpose of the study is to illustrate how the frameworks of Gibson and Earley (2007) and Lovaglia et al. (2003) can be used in practice in management accounting research. Hence, this study is both an interpretative one and illustrative one at the same time (Lukka, 1999), while it is based on interpretative approach, but at the same time it is illustrating how the collective action theory could be used in management accounting research..

The rest of the paper is structured as following. Firstly, we describe earlier studies concerning the collective action theory and how it is applied in the current study. Secondly, we present methodology and case organization. Thirdly, we present empirical results; how the actors of a case organization affected the EMS and PMS implementation. Empirical part also analyzes the power and status of actors of the EMS and PMS implementation. Finally, we consider the contribution of study.

\section{Earlier collective action theory studies}

There could several different theories which could be used for investigating the phenomena. One attractive alternative could be Latour's actor-network-theory (ANT) (Baxter and Chua, 2003). We are not utilizing the ANT because it does not specifically separate specifically power and status of actors (see for instance Callon, 1998). Moreover, we were not interested in the roles of non-human 
actors in the change processes in this study. Furthermore, there are already a larger number of earlier studies which has recently utilized ANT than collective action theory (e.g. Alcouffe et al., 2008; Hyvönen et al., 2008), which could hence provide more novel interpretative insights to the study at hand. These viewpoints led us consider collective action theory to be better alternative for our purposes. However, we encourage also the potential usage of actor-network theory in further studies in order to gain new and contemporary insights to the EMS and PMS developments in different types of organizational settings. ANT could be particularly fruitful, if also the roles of the non-human actors will be taken under analysis.

Collective action theory seemed particularly suitable for several reasons. First, this theory focuses on conditions under which organizations and institutions collaborate to achieve common goals (Flanagin et al., 2006; Markus et al., 2006). Secondly, we share the idea of Hargrave and Van de Ven (2006) that collective action theory might be an important addition that complements the existing repertoire of models of change in the institutional literature because it considers exactly how the actors and their abilities affect in change process. Third, some models of collective action theory include explicit factors concerning individual, organizational and cultural characteristics (e.g. Gibson and Earley, 2007; Tang 2008). We consider these factors important also when companies are changing their PMS. On the other hand, the models of institutional theory such as Burns and Scapens (2000 see also Kasurinen, 2002) do not specifically investigate the role of individual factors and thus these models are not suitable for our purposes as such. Fourthly, some collective action models propose explicitly how status (Gibson and Earley, 2007) or status and power affect together (Lovaglia et al., 2003) operations. Finally, we did not find empirical studies where the phenomena were investigated with the selected collective action theory, which attracted our scientific curiosity even more.

Earlier institutional theory studies have widely examined how organizations adapt and conform to institutional environmental pressures in order to achieve legitimacy (e.g. DiMaggio and Powell, 1983; Meyer and Rowan, 1977; Scott, 2001). They have also examined the diffusion of institutions among organizations (Carroll and Hannan, 1989) and how institutional entrepreneurs affect institutional change (Garud et al., 2002; Rao et al., 2003). Institutional theory is also applied in management accounting research (e.g. Burns and Scapens, 2000; Lukka, 2007; Soin et al., 2002). These institutional theory studies have explained how institutional arrangements are adopted and diffused, but they have not illustrated much about the process of collective action through which institutions are created (Hargrave and Van De Ven, 2006). Furthermore, Lounsbury (2008) recommends further practice oriented studies which investigate if collective action is required in implementing manage- 
ment control systems and the creation of a new logic in organizations. On the other hand, these earlier institutional studies have not specifically investigated how different actors and their capabilities, power and status affect the change process.

A collective action theory can be used to investigate institutional change which considers also the individual and organizational effect on group performance (e.g. Gibson and Earley, 2005; Hargrave and Van De Ven, 2006; Tang, 2008). Collective action theory emphasizes the focus on the role of a group in a change process. According to Hargrave and Van De Ven (2006), the collective action model examines the construction of new institutions through the political behaviors of many actors who play diverse and partisan roles in the organizational field or network that emerges around a social movement or technical innovation. Hargrave and Van De Ven (2006) continue that collective action researchers are primarily concerned with how new institutional arrangements emerge from interactions among interdependent partisan agents. The mode of interaction can vary from direct personal interaction to indirect impersonal interaction (Flanagin et al., 2006). Therefore, collective action theory provides a new model of institutional innovation and change that supplements and extends existing models of institutional change (e.g. Burns and Scapens, 2000 see also Lounsbury, 2008).

There is available some conceptual models which are based on collective action theory (e.g. Gibson and Earley, 2007; Lovaglia et al., 2003; Tang, 2008). One conceptual collective action model is created by Gibson and Earley (2007). Their conceptual model enables to explain how group efficacy develops and operates within existing groups (Gibson and Earley, 2007). Group efficacy is defined as a "group's belief in its capability to perform a task objective" by Gibson and Earley (2007). According to the Gibson and Earley (2007) model, eight variables affect group efficacy. Their model has also three moderating variables between group efficacy and performance. The model of Gibson and Earley (2007) has three phases of development and operation of group efficacy; information gathering for efficacy development, interaction and examination and finally accommodation of information. Gibson and Early (2007) present eleven propositions and five moderating factors which affect group performance. These propositions are classified into three different development phases of group efficacy. We focus on two propositions of Gibson and Earley (2007); how actor abilities (P1) and their roles (P7) influence EMS and PMS construction in a case company. We selected intentionally particularly these two propositions of Gibson and Earley (2007) because they focus the role of actors and their abilities, which are in the core of our analysis in this study. Therefore, we considered that these two propositions fit our purposes at the best. 
Tang (2008) has developed another conceptual collective action theory model. Tang (2008) model has five sets of variables which affect people's contribution to public good. Tang's (2008) variables are individual characteristics, organization characteristic, cultural characteristics, leadership, features of public good as well as the interaction among them. Tang (2008) defines three dimensions for public good which are relating to individual, organizational and societal dimensions. The public good may relate for instance to the implementation of an information system if this information will improve decision making as well the satisfaction of the IS users in an organization. Tang (2008) model is quite similar as Gibson and Earley (2007). However, the model of Gibson and Earley (2007) focuses more on group than Tang (2008). On the other hand, Tang (2008) model consider also cultural and leadership characteristics more explicitly than Gibson and Earley (2008) model.

Third conceptual model of collective action is developed by Lovaglia et al. (2003). This model is more focused than Tang (2008) and Gibson and Earley (2007). Eleven propositions of Lovaglia et al. (2003) model enable to investigate how power and status affect collective action. Lovaglia et al. (2003) propose for instance that status attainment can motivate individuals to contribute public good. They also propose that the greater the expectations for an actor's contribution to the group, the greater that actor's status. According to the Lovaglia et al. (2003) proposition, the greater an actor's resources (i.e. power), the greater will be the expectations for that actor's contributions to the group. We consider that Lovaglia et al. (2003) conceptual model is also usable for our purposes because their model specifically focuses on actors' power and status. On the other hand, the model of Lovaglia et al. (2003) has a limitation because it does not illustrate conceptual linkages between eleven propositions or draw an explicit model. However, this limitation does not prevent us to apply their model because we are not conducting any statistical analysis.

Despite different conceptual models of collective action theory, we found only a few empirical studies which have used collective action in different settings (Chou et al., 2008; Jarzabkowski and Searle, 2004; Markus et al., 2006; Vogel, 2005). The most of these empirical studies are qualitative case studies (Chou et al., 2008; Jarzabkowski and Searle, 2004; Markus et al., 2006). Vogel's (2005) case study integrates both qualitative and quantitative methods. Case studies are conducted in public sector (Chou et al., 2008; Jarzabkowski and Searle, 2004), industrial level (Markus et al., 2006) both private and public companies (Jarzabkowski and Searle, 2004; Vogel, 2005).

The collective action theory is applied for several different purposes (Chou et al., 2008; Jarzabkowski and Searle, 2004; Markus et al., 2006; Vogel, 2005). Chou et al. (2008) use collective action theory in the development of e-government. Chou et al. (2008) investigate nine collective action problems and their effects on collective action. According to the study of Chou et al. (2008), prob- 
lems related to motivational (e.g. social value orientation, communication and group identity) and structural dimensions (i.e. efficacy, group size and sanctions). Jarzabkowski and Searle (2004) evaluate how top management diversity impacts on top management strategic capacity. Jarzabkowski and Searle (2004) use three levels to evaluate team diversity; demographic, informational and behavioral. On the other hand, Markus et al. (2006) studied vertical information systems standardization which analyzes both standards development as well diffusion of these standards. Markus et al. (2006) investigated collective good, collective active dilemmas, heterogeneity of resources and interests in these two phases of standardization process. Vogel's (2005) study investigates network action in a change process. Vogel (2005) found that collective action of networks was affected statistically significantly by individual action, collective cognitive processes, collective volition and supportive context. As can be notified, these earlier empirical studies are not conducted in field of EMS, PMS or management accounting in general and thus more empirical collective action research in the field of EMS and PMS is requested.

Our study differs from the above described empirical studies. First, we focus on different application area (cf. Chou et al., 2008; Jarzabkowski and Searle, 2004; Markus et al., 2006; Vogel 2005). Second, we focus on a single company (cf. Jarzabkowski and Searle, 2004; Markus et al., 2006; Vogel, 2005) in a private sector (cf. Chou et al., 2008). Third, our study investigates the specific group which was established only to implement of EMS and PMS (cf. Jarzabkowski and Searle, 2004). Finally, we concentrate on using qualitative case method to investigate the phenomena (cf. Vogel, 2005).

This study utilizes both the frameworks of Gibson and Earley (2007) and Lovaglia et al. (2003). We had some major reasons to apply these particular frameworks. First, the Gibson and Earley (2007) framework focuses on group efficacy which they define as a group's belief about its perceived capability to perform a specific task objective. The framework focuses also on workgroup i.e. a small number of interdependent actors as opposed to large set of people (Gibson and Earley, 2007). Second, the framework of Gibson and Earley (2007) is a new and recently developed and subsequently interesting for empirical testing. Thirdly, the framework of Lovaglia et al. (2003) specifically focuses how the power and status of actor affect collective action. Fourth, these frameworks are conceptual and we want to test their suitability with empirical data in our case study in management accounting research. Finally, we did not find any other study which has used these frameworks before to investigate this kind of phenomena. The research questions of this study are the following:

Research question Ia How the abilities of actors, their roles, power and status affect in construction a greener PMS? 
Research question Ib How capable are the frameworks of Gibson and Earley (2007) and Lovaglia et al. (2003) for investigating and illustrating actor abilities and its effect on group performance in a single case study?

\section{Methodology}

\section{Used methods}

We used an interpretative case study approach in this study. We were not testing a hypothesis or trying to make any statistical generalizations. Therefore, the results of the study can be generalized as rather more theoretically or contextually than statistically. (see for instance Ahrens and Chapman, 2006; Ahrens and Dent, 1998; Enquist et al., 2006; Lukka and Kasanen, 1995; Modell, 2005; Vaivio, 2008; Woodside and Wilson, 2003). According to Modell's (2005 see also Vaivio, 2008; Woodside and Wilson, 2003) classification, the result of this study can also be used for generating a hypothesis which can be tested by a survey later.

The empirical data was collected via a preliminary interview of the Technical Director and Quality Manager of an international Finnish company and ten semi-structured follow up interviews. These two representatives were selected for the preliminary interviews because they were the contact persons named on the company's web pages. They were also responsible for running the environmental management policy and dealing with any issues that arose. The preliminary interview was justified for several reasons (see also Ribeiro and Scapens, 2006; Rothenberg, 2007). First, we wanted to present our research project and evaluate the case company's willingness to participate. Second, we acquired more empirical information on how environmental and performance management issues operated in practice.

Semi-structured interviews are a common method used in collecting qualitative data and consequently this method is also used in this study (see examples in Lee and Humphrey, 2006; Lukka, 2007). We wanted to interview different directors to achieve a better understanding of the phenomena. The interviewees' responsibilities varied from unit management, through business area management, to board level functional responsibility within the largest subsidiary and group. We had a good access to the case organization. Therefore, we were able to interview all representatives who were necessary for our research purposes.

Both researchers participated in all the interviews. The interviews were recorded on tape and transcribed onto paper (see for instance Rothenberg, 2007; Burns, 2000). We read the transcribed interviews several times to contribute research questions and understand the phenomena (Ahrens and 
Chapman, 2006). We identified the actors and their abilities in implementation of the two management systems by re-reading and indexing. After indexing, we organized the data so that internal actors formed one group of actors and the external actors formed another group.

We usually spent from one to two hours in the company and the duration of interviews varied from forty to ninety minutes. All the interviews were conducted in the company, and in the interviewees' native language. Therefore, all the quotations in the article have been translated into English, and consequently, different shades of meaning may emerge due to the translation, even though we have tried to be very careful in conducting the translation.

We have utilized several modes of triangulation to increase the trustworthiness of our study (Ahrens and Chapman, 2006; Vaivio, 2008; Woodside and Wilson, 2003 see also Lee and Humphrey, 2006; Modell 2005). First, we utilized several different types of data i.e. annual reports, public documents, personal e-mails and interviews. Second, our interviewees had both horizontally and vertically different positions. Third, both researchers participated in all interviews, which enabled researcher triangulation. Fourth, we allowed as much time for interviewing and observing in the case company as was possible.

\section{Case organization}

The case company is the Finnish meat processing company. The case company has bought subsidiaries abroad and invested in a plant in the last decade. It publicly reports on its environmental performance by dedicating one part of its official annual report for the purpose (for a similar reporting policy, see for example Enquist et al. 2006). It also produces a separate environmental report which is not published annually.

The case description is based on the company homepage, published reports, the company management system and interviews. Our case site is a Finnish food manufacturing company, which is the largest subsidiary company of a larger group. Its turnover exceeds EUR 700 million and has been increasing in recent years. The group is becoming increasingly international. The case company is responsible for the group's domestic operations, and its customers include retailers, catering enterprises, industry and the export trade. The case company has some production plants in Finland.

\section{EMS, PMS and their integration in a case organization}

According to its current (approved in 2006) management system, the company 'recognizes its environmental responsibility. It has an environmental programme aiming at controlling the use of natural resources and preventing environmental damage. It is committed to the principle of sustainable 
improvement.' Therefore, its executives recognize the environmental risks and impacts of their operations and set goals according to them. Environmental programmes were first prepared for a five year period (2001-2005) and now span three-year periods in order to achieve the set goals.

According to the management system, the Quality Manager is responsible for ensuring that the environmental system incorporates the elements and procedures of the ISO 14001 standard. The Technical Director and operations engineers are responsible for planning location-specific environmental investments and for monitoring their progress. The Quality and Technical Managers were the key developers of the environmental management program.

The EMS is based on the ISO 14001 standard which was granted in 1995. According to the published environmental programme, it tries to ensure that the set objectives are achieved. Furthermore, the programme communicates the company's environmental responsibility and the focus on continuous improvement of its operations to interested groups. The aim is to minimize the environmental impacts of production and thus also keep expenses as low as possible. The company has set objectives for reducing the use of energy and natural resources. In addition, it continuously seeks to improve the level of environ-mental protection in its operations.

The published environmental programme states that environmental issues and their related environmental impact are recognized within each production unit and unified within the company's environmental programme. Environmental impacts are evaluated and the company pays attention to all significant issues in terms of environmental protection and its business. Environmental conditions required for operations have been documented, and their progress is regularly monitored via internal reviews.

The company decided to implement a BSC performance measurement system called 'Argon' in 2004, that is, many years after the original ISO14001 certification. The case company utilized one Finnish software vendor for implementing PMS. They decided to include environmental measures in the PMS during the process of BSC implementation. The PMS consists of the four common perspectives (financial, customer, internal processes and learning and growth) and the environmental targets and measures were included in the processes perspective.

This EMS integration into PMS had at least to reasons. First, they wanted to integrate their fragmented information systems. Secondly, the integrated PMS can be used by everybody who is authorized user. Thirdly, they wanted to measure also other measures than only financial measures. The following quotations illustrate these reasons. 
"when we have learned this balanced scorecard again and again, that we have to investigate our performance in that [multidimensional] way, thus, according to my knowledge they [environmental issues] adjust somehow to that world [of balanced scorecard] ... If we wanted to be prospectors and inform stakeholders about these [environmental] issues. Then we have to inform about [environmental] issues also our own staff and we have to find these [environmental] issues somewhere [data systems]" (IT director)

"It's [Argon, i.e. PMS] usable for everyone of course with certain passwords... when we add the numbers [i.e. values of indicators] into Argon, they are centrally in the [one PMS] system.” (Technical director)

\section{Empirical results analyzed by utilizing collective action theory}

Empirical part of the study follows hereafter the one part of model of Gibson and Earley (2007). We will analyze how and what actors affected in implementation of EMS and PMS. We dichotomize actors as internal and external actors. Internal actors are directly operating in a case company and they are employees of the company. External actors are indirectly operating with case company. External actors are not employees in the company.

\section{Actors}

\section{Internal actors of organization}

The case company has several key actors in the process of implementing the EMS and PMS. We found that the key participants differ between the constructions of two management systems. Quality manager and Technical director were the two key participants in implementing EMS whereas controller, IT director, Quality manager and Technical director were the key participants in constructing PMS. The both construction groups of management systems had also other participants with a minor role.

"environmental aspects were considered with representatives of business areas and quality manager... these environmental measures are based on historical trend and an assumption what has happened in these companies. After that I and quality manager and [two employees] have discussed and considered these measures. After that [dis- 
cussion] we have presented these measures to the executive board of directors" (Technical director)

"Technical director has an extreme central role [in EMS]. He practically executes these [EMS] issues or is responsible for executing these [environmental management] systems.... quality people [quality manager] and technical service [technical director] have had always key roles in target setting and generally environmental issues because they know technology and its opportunities." (Quality director)

"the employees in technical service and I [quality manager] has been in cabinet [for constructing environmental measures... there was quality manager, controller and IT directors [participants in constructing PMS]" (Quality manager)

"Business area directors, quality organization, quality manager, technical part of organization and the external auditor of [environmental system] has been constructed and selected the [environmental] measures" (Business area director)

“We [unit managers] haven't been implementing environmental management systems... Both quality manager and technical directors have implemented the environmental program and environmental measures" (Business unit manager)

The CEOs of the group had different roles in implementation of EMS and PMS. One of the earlier CEO's roles was to introduce as well motivate profit-oriented culture, particularly the high cost conscious. The earlier CEO of group has retired a half year before we launched our research project. The new CEO, who was interviewed in the study, continued to emphasize the profit orientation. He also highlighted the revenue side of the profit consciousness. This culture was mentioned in many interviews in different organizational levels.

"we've experienced that our staff understand better euros than kilowatt hours or tons of oil. Euro is suitable... my most important task is to improve profitability! If we aren't profitable, we've to do something" (CEO of the group)

"money is the greatest incentive.... when we use currency to measure then we achieve progress... all the issues which we transport to landfill, it will cost." (Business area director)

"Yeah, it [the achievement of environmental targets] has effect on financial performance and profitability, if we consider for instance that today energy is expensive, the decreased energy consumption leads to lower costs" (Unit manager) 
In addition to establishment of this profit-oriented culture, the CEOs have tried to strengthen the measurement culture in a case company. Several interviews in the different organizational levels revealed believe concerning the advantages of measurement culture.

"we should focus on factors which are certain essentially important and complete these factors well. If we control hundreds of factors, we don't control any factor. It's the basic setting. This wasn't statement how we have operated" (CEO of the group) "you achieve changes when you're able to deliver indicator's results to these employees who make decisions... [the measurement culture and cost control] are deep in our culture and we will not destroy them." (CEO of the largest subsidiary)

"we've to know critical success factors... we've to measure these critical factors and tell for people the direction [where the performance is developing]... we've to be able to operationalize vision, values and strategy..." (IT director)

“as a quality manager, I've learned that if you can't measure that you can't manage and improve" (Quality manager)

"I want to utilize measures in [PMS] as a management tool... the truth is; what you measure that you achieve" (Unit manager)

However, the role of CEOs had changed during the implementation of EMS. In the beginning of EMS project, the earlier CEO had a central and active role but the current role of the new CEO is more passive and subsequently EMS issues are more operated by experts. This is because he has currently many other managerial challenges to handle.

"I've spent my effort on restructuring this company the last half year, my level of troubles has been different... this kind of issues [implementation of PMS and EMS] which has been operating fairly well, I haven't spent much time at all. Primarily I've been abroad, restructuring of company... we've had troubles in our profitability since the beginning of the year... Let's say the sustainable development hasn't had the highest priority in our agenda" (CEO of group)

"In the beginning of EMS implementation, the CEO's role was central. CEO has spent a lot of effort that our company environmental actions have received [external] publicity. They have published different tracts and flyers and information briefings because it [environmental management system] was a brand new. Then CEO did really what 
CEO can do; allocate money for continuing that project... today, CEO has changed the responsibility for experts." (Quality manager)

One role of executive directors was to be as a catalyst for utilizing PMS to other employees. Especially IT director and CEO of the largest subsidiary emphasized their role as a motivator for increasing the utilization. They thought that the PMS could be used especially for monitoring the business success in more detail.

“we will begin to use it [Argon]. We will utilize it in every board of directors' meeting, otherwise it doesn't be implemented. When we use [Argon] in every meetings monthly, it will be used also in lower levels" (CEO of the largest subsidiary)

"my personal target is that we've to increase PMS utilization... we haven't used [PMS] enough in our subsidiary board of executive directors. I'm personally responsible that [PMS] will be utilized... logistics measures which I'm responsible for I present there [meeting of board of executive directors]... if the director is interested in these measures also other employees are interested in these measure. If the director is not interested in these measures, then also others aren't... our official target is that Argon will be a real management tool in subsidiary's board of executive directors" (IT director)

Technical director was a key actor in implementing EMS. This director was determining the environmental targets for EMS. In the end of the fieldwork period, they were trying to implement the practical operations of environmental management more in departments, production units and business areas. One reason for this is that business areas and their managers have notified the importance of environmental management and the linkage between environmental and financial performance. Quality director admits that Technical director and Quality manager were the key participants in target setting and in constructing environmental management system although production units participated also in this target setting process. Quality director justified this mode of operation by saying;

“..they [technical service and quality people] know technology and its opportunities” [Quality director]

Technical director and business area director give reasons why the construction of EMS has been a technical issue in more detail. EMS has been technical issue because the indicators of EMS has related to technology. 
"This has been technical issue because it requires technical actions and implementation; transportation of garbage and operation of sewage disposal, electricity availability, heat production, the construction of heat recovery" (Technical director) "production feels that .... they can't affect these [levels of environmental measures] ... these environmental indicators measure usually some kind of technical issue such amount of waste, waste water or consumption of electricity, water and oil. Production staff feels that these [environmental] issues are predetermined and their task is to produce the target amount of products which requires a certain amount of oil, water... they consider that they cannot affect on these [amounts of consumption]. In our company, this [environmental] issue is a technical issue" (Business area director)

However, some interviewed observed also the focus on technical issues concerning the construction of environmental management program although the focus is changing toward practical operations. Therefore, they are trying to change responsibility about the achievement of environmental indicators from technologic to production department.

"[the real challenge] is the implementation. We have to find the real responsible person in production who describes the reasons why an indicator is on some level. Therefore, the responsible person cannot be quality manager or technical director" (Controller)

"production assumes that they can't affect on [environmental issues]. These environmental targets measure technical issues such as garbage... the production employees assume that [the measures] are given and their task is just to produce... they feel that [technical director] is responsible about environmental control although production is naturally only responsible who is able to affect and anyone else." (Business area director)

Quality manager was also a key actor in implementing EMS system. According to technical director, they did not want to establish a specific department for considering environmental issues. According to internal documents, the case company has achieved the quality certificate before EMS. The quality manager is by definition responsible about the quality issues and the operations which are required by quality certificate. They thought that quality and environmental issues have many similarities and thus the same representatives can be responsible both quality and environmental issues. The quality manager himself considered that he has tried to emphasize the importance of different measures for managing business. The quality manager thought that the lack of company 
wide consistent measures leads the difficulties in controlling and reporting especially the quality issues. On the other hand, quality manager also thought humoristic that achievement of EMS can be used for legitimizing the work of quality manager.

"why quality and environmental issues are interconnected (interviewer)? It's the most effective way to execute this area. We didn't want to construct any specific separate environmental department, it's this comprehensive control... the same people operate with these similar things" (Technical director)

"Quality manager has been responsible for developing these [environmental] management systems" (Controller)

Therefore, the directors thought that quality manager has capabilities to implement EMS because quality manager has had capability to implement quality management system before the implementation of EMS. Also a unit manager trusted the capabilities of quality manager which can be observed in the following citation;

"Quality manager has succeeded to sell [environmental program] us. Therefore, we believe that the targets are realistic and we can reach them." (Unit manager)

Business area directors had a minor role in implementing EMS although they were analyzing and the environmental targets and actions.

"we [quality manager and technical director] presented environmental aspects and impacts to them [business area directors]. When we again investigated [environmental aspects and impacts] they [business area directors] were more actively investigating these issues. After that [more active role], they realized that these are our environmental aspects and impacts and we [business area directors] have to establish targets for these environmental aspects" (Quality manager)

Unit managers did not have a direct role in implementing EMS. Unit managers have discussions with quality manager and technical director how to achieve the targets in practice. On the other hand, unit managers have their own managerial discussions with production supervisors about the success of environmental targets inside their own units.

"we [quality manager and technical director] talk with unit managers about their assignments [concerning environmental issues] if you [unit manager] have understood these different [environmental] issues and what does it mean water recycling or inves- 
tigation of new potential recycling stuff from your own perspective" (Quality manager)

"we discuss with quality manager, technical director and production supervisors about environmental measures and how the environmental targets are achieved. The measures are not available in the lowest 'floor' level" (Unit manager)

Controller was a key actor in especially implementation of PMS in practice. Controller added for instance the selected measures into different perspectives of PMS. According to Controller, he advised other PMS users how the selected PMS software is practically operating. The Controller also developed PMS and its process hierarchy. Controller was also a actor and consultant in different PMS project meetings. Finally, the controller was the manager of project secretary and a contact person between the IT department of a case company and software vendor.

“Are you [controller] responsible in Argon [PMS] project? (Interviewers) Yes, I am" (Controller)

\section{External actors of organization}

In addition to internal actors of the organization, the case company had also external partners who participated in EMS and PMS implementation. These external actors consist of certifying company, local environmental authorities and one key customer.

A certifying company was a participant in EMS implementation and especially in EMS certification process. This standardizing company advised for instance in the selection of environmental targets. Their role has widened from environmental auditing company to consultancy when they suggest sometimes how the case company might improve its operations in practice.

"They [standardizing company] have also a developer role nowadays. It's not only auditor who grades the environmental issues. Nowadays, we have quite good discussions with these [environmental] auditors concerning how we could develop our performance" (Technical director)

"standardizing company has advised [for instance] if it would be worthwhile to investigate unit or industrial sector specific amounts of municipal solid waste" (Quality manager)

Local environmental authorities have a minor role in implementing EMS. They have effect especially when the case company is constructing the indicators of EMS. 
"environmental authorities has set basic levels [of environmental targets]. When we are applying different permissions we've to define different issues such water consumption and emissions... The environmental authorities have been advising and guiding these [environmental permission] issues." (Business area director)

"we have to control the measures which are in environmental permissions. Therefore, these [environmental measures] are included into environmental program; they are 'must' issues which have to be achieved" (Technical director)

One largest customer of case company had also a similar PMS what they decided to implement. This customer role was not very significant in implementation itself but it enabled a case company to learn how the customer was implemented and used the selected PMS software.

"one of our main customer have been utilized this same [PMS] software in practice. This kind of co-operation projects enabled us to investigate what they have done and we became more experienced [concerning the certain PMS]" (IT director)

The customers had even less important role in implementing EMS than PMS. The customers did not advice in EMS implementation or they did not force the company to apply environmental certificate. According to the Quality Director on the group executive board, the case company certified its EMS so early that customers were not aware of any requirement for the certification.

"we were prospectors. We got the environmental certificate at the first in Scandinavia in meat industry. We were so prospector that customers didn't request" (Quality director)

\section{Analysis of empirical results}

\section{Actors in implementation and their specific contribution areas}

As we described earlier, the case company had both internal and external actors when they were implementing both PMS and EMS. These actors were able to contribute only a small amount of the public good because they had knowledge only of their own responsibilities (see for instance Markus et al. 2006). For instance, the earlier CEO promoted euro-driven culture or IT director had knowledge concerning general requirements of company's information systems. Quality manager knew the requirements concerning environmental certificate and technical manager perceived technological possibilities concerning environmental performance. On the other hand, controller had 
knowledge about performance measurement systems. Table 1 illustrates actors in construction of two management systems, both organizational level and specific contribution areas of actors.

Table 1 Different actors and their specific contribution in the area of the research topic

\begin{tabular}{|c|c|c|}
\hline $\begin{array}{l}\text { Actor } \\
(\mathrm{e}=\text { environmental, } \\
\text { p=performance) }\end{array}$ & $\begin{array}{l}\text { Level in a organ- } \\
\text { ization }\end{array}$ & Specific area of contribution \\
\hline \multicolumn{3}{|l|}{ Internal actors } \\
\hline CEOs $(e, p)$ & Group & $\begin{array}{l}\text { To promote "Euro-driven" and measurement culture into com- } \\
\text { pany. To inform external stakeholders how the company is im- } \\
\text { plementing its EMS. }\end{array}$ \\
\hline $\begin{array}{l}\text { CEO of the largest } \\
\text { subsidiary }(p)\end{array}$ & $\begin{array}{l}\text { Group and the } \\
\text { largest subsidiary }\end{array}$ & $\begin{array}{l}\text { Organization the meetings of steering committee in the largest } \\
\text { subsidiary; the utilization of new information systems }\end{array}$ \\
\hline IT director $(\mathrm{p})$ & Group & State of art group IS; requirements and development \\
\hline Controller $(\mathrm{p})$ & $\begin{array}{l}\text { The largest sub- } \\
\text { sidiary }\end{array}$ & $\begin{array}{l}\text { Responsible about constructing BSC performance measurement } \\
\text { systems in practice }\end{array}$ \\
\hline $\begin{array}{l}\text { Quality manager } \\
(\mathrm{e}, \mathrm{p})\end{array}$ & $\begin{array}{l}\text { The largest sub- } \\
\text { sidiary }\end{array}$ & $\begin{array}{l}\text { Requirements concerning environmental certificate } \\
\text { measures in general. }\end{array}$ \\
\hline $\begin{array}{l}\text { Technical director } \\
\text { (e) }\end{array}$ & $\begin{array}{l}\text { The largest sub- } \\
\text { sidiary }\end{array}$ & $\begin{array}{l}\text { Technological opportunities to improve environmental and fi- } \\
\text { nancial performance }\end{array}$ \\
\hline $\begin{array}{l}\text { Business area di- } \\
\text { rectors and Unit } \\
\text { managers }(\mathrm{p})\end{array}$ & $\begin{array}{l}\text { Sectors in a the } \\
\text { largest subsidiary } \\
\text { and plant }\end{array}$ & $\begin{array}{l}\text { Execution of required operative and practical actions concerning } \\
\text { improvement of environmental and financial performance }\end{array}$ \\
\hline \multicolumn{3}{|l|}{ External actors } \\
\hline $\begin{array}{l}\text { Local environmen- } \\
\text { tal authorities (e) }\end{array}$ & External partner & $\begin{array}{l}\text { Requirements concerning environmental targets and documenta- } \\
\text { tion }\end{array}$ \\
\hline $\begin{array}{l}\text { Certifying compa- } \\
\text { ny (e) }\end{array}$ & External partner & $\begin{array}{l}\text { Required improvements needed to achieve environmental certif- } \\
\text { icate. Recommendation to improve performance and environ- } \\
\text { mental targets. }\end{array}$ \\
\hline $\begin{array}{l}\text { A major customer } \\
\text { (p) }\end{array}$ & External partner & $\begin{array}{l}\text { Recommendations and experiences concerning a specific per- } \\
\text { formance management system. }\end{array}$ \\
\hline
\end{tabular}

According to Table 1, participants had different specific knowledge areas. Table 1 illustrates that the company had several different participants from several different organizational levels. In addition to internal actors, the project group had also external partners such as local environmental authorities, certifying company as well as major customer. A major customer utilized the chosen PMS software. The customer recommended and told their experiences concerning this performance management system. The case company selected this same performance management system later.

We found that the actors were different in implementation of EMS and PMS although these two systems were decided to integrate later. The key actors in EMS implementation were Technical director and Quality manager. On the other hand, IT director and controller were the key actors in implementation on PMS. 


\section{Roles of actors in implementation}

We found that both internal and external actors had different roles in implementation. This analysis separates the status and power (Lovaglia et al., 2003) which both affect the role of the actors in implementation. Lovaglia et al. (2003) defines power as the structurally determined potential for obtaining favored payoffs in relations where interests are opposed. Burns (2000) categorizes power into three dimensions; power over resources, power over decision making and power over meaning. Lovaglia's et al. (2003) power definition is close to the concept of power over resources proposed by Burns (2000). The status is defined by Lovaglia et al. (2003), as a person's position in a group's prestige hierarchy. We follow the status and power definitions of Lovaglia et al. (2003) in the following analysis.

\section{Internal actors' roles in implementation}

We found that the CEO of the group has promoted successfully "euro-driven" and measurement culture in a case company. Therefore, CEO's individual characteristic led to the changing culture in a case company (see Tang, 2008). On the other hand, the high power of CEO enabled to change organizational culture toward measurement culture (Burns, 2000; Lovaglia et al. 2003). However, the CEO of the group status diminished during the implementation of EMS and PMS although he had still power to change organizational culture or to finish the implementations of both systems. The status of CEO of the group was in practice low because CEO did not attend to different implementation meetings. CEO had a high status in the implementation team of EMS in the beginning but his status decreased during the course of implementation.

We consider that IT director and CEO of the largest subsidiary had high power in case company because they are actors of executive board of group. Therefore, they are able to launch and finish different implementation projects such as EMS or PMS. The CEO of the largest subsidiary and IT director had also power to motivate other managers to use new PMS in different meetings. This "push" was conducted in a way that they themselves use PMS to illustrate the success of their own responsibilities in different meetings. IT director had higher status than CEO of the largest subsidiary in implementation of PMS because IT director had a key role when was decided to invest on new PMS. IT director knew how the current systems should be improved so that these systems could support decision making. IT director had also a high status in implementation group because his employee (controller) implemented PMS practically.

Quality manager, Technical director and business area directors have average power when they have for instance their own budgets. We consider that for instance Quality manager does not have 
high power in implementation because quality manager is expected to conduct the required issues that the EMS certification would be achieved. On the other hand, Quality manager, Technical director and Business area directors are not able themselves to launch or finish the EMS and PMS implementation. Although these directors have similar (average) power their statuses have differences from high to low. Quality manager and technical director had a high status in EMS implementation because they were key actors in the selection of EMS indicators. The status of Quality manager and Technical directors were high in the EMS certification because the case company has already achieved quality certification. This quality certificate was an evidence of capabilities of quality manager and technical director. Furthermore, quality manager and technical director investigated how environmental targets have been achieved and what operations are required in business units. This kind of investigation was conducted together unit managers. The status of business area directors and unit managers was low in implementation of EMS and PMS. The business area directors and unit managers were not responsible in implementation although they were analyzing environmental targets.

We consider that Controller had a lowest power in implementation of PMS although the controller had an employee (project secretary) in the construction of PMS in practice. The controller did not have power to force decision makers to utilize a new PMS. Despite of the low power, the controller had a high status in PMS implementation. The controller had experience also how the indicators can be constructed and added into PMS. The controller knew how EMS and PMS integration can be practically conducted with existing softwares which again increased the status of controller. On the other hand, the status of controller increased during the implementation when the PMS software was selected. After this selection, the controller was a link between the case company's IT department and software vendor and educated new users to utilize the new PMS. Therefore, the controller had a low power and high status in the implementation of PMS.

\section{External actors' roles}

All the external actors had low power in implementation of EMS and PMS. Therefore, customers, local environmental authorities or certifying company did not force company to implement EMS or PMS. On the other hand, the certifying company has power to accept or reject the case company's EMS certification.

All the external actors, except certifying company, had also a rather low status in implementation. The certifying company had average status in EMS implementation when it provided advice how the practical operations and environmental indicators could be performed. The status and role of 
certifying company enlarged from auditor to consultant during the course of implementation. Therefore, the status is rather dynamic than static when the status changes during implementing management systems.

As can be notified in earlier paragraphs, the status and power are different concepts (see also Lovaglia et al., 2003). This means that high power does not result high status in the group of implementation. In addition to this difference between these concepts, the status of actors can change during the implementation. The status was decreased among actors who had the highest power and status. On the other hand, the status was increased with the lower power and status actors during the implementation.

To summarize this section, Table 2 illustrates different key actors and their status and power in implementation EMS and PMS. These levels of power and status are assessed by authors after conducting interviews and reading several times the transcript interviews. Therefore, the levels of power and status are subjective and they are not based on any objective measure. 
Table 2 Assessed power and status of the actors in implementation of EMS and PMS

\begin{tabular}{|c|c|c|c|}
\hline $\begin{array}{l}\text { Participant }(e=E M S, \\
p=P M S)\end{array}$ & Power & Status & Reasons \\
\hline \multicolumn{4}{|l|}{ Internal actors } \\
\hline CEOs $(e, p)$ & High & $\begin{array}{l}\text { High } \rightarrow \\
\text { Low }\end{array}$ & The final acceptance for project \\
\hline $\begin{array}{l}\text { CEO of the largest } \\
\text { subsidiary }(\mathrm{p})\end{array}$ & High & Average & $\begin{array}{l}\text { Recommendations to CEO of group, can force business area direc- } \\
\text { tors to use systems in steering committees }\end{array}$ \\
\hline IT director $(\mathrm{p})$ & High & High & $\begin{array}{l}\text { Recommendations to CEO, can force controllers to construct dif- } \\
\text { ferent management systems, can give an example as an user of } \\
\text { greener PMS for others. }\end{array}$ \\
\hline $\begin{array}{l}\text { Quality manager } \\
(\mathrm{e}, \mathrm{p})\end{array}$ & Average & High & $\begin{array}{l}\text { Can force unit managers to report environmental performance. The } \\
\text { selection of used EMS indicators. Meetings with unit managers } \\
\text { how environmental indicators are achieved. }\end{array}$ \\
\hline $\begin{array}{l}\text { Technical director } \\
\text { (e) }\end{array}$ & Average & High & $\begin{array}{l}\text { The creation of EMS together quality manager. Meetings with unit } \\
\text { managers how environmental indicators are achieved. }\end{array}$ \\
\hline $\begin{array}{l}\text { Business area direc- } \\
\text { tors and Unit man- } \\
\text { agers }(p)\end{array}$ & Average & Low & $\begin{array}{l}\text { Required operative and practical actions concerning improvement } \\
\text { of environmental and financial performance. Unit managers con- } \\
\text { trol the achievement of measures with production supervisors }\end{array}$ \\
\hline Controller $(\mathrm{p})$ & Low & High & $\begin{array}{l}\text { Can force only the project secretary. On the other, controller has } \\
\text { the best knowledge on constructing PMS in practice. Controller } \\
\text { has also the closest relations with IT department and software } \\
\text { vendor and a teaching responsibility of new users of PMS. }\end{array}$ \\
\hline \multicolumn{4}{|l|}{ External actors } \\
\hline $\begin{array}{l}\text { Local environmental } \\
\text { authorities (e) }\end{array}$ & Low & Low & Possible requirements in documentation in future investments \\
\hline $\begin{array}{l}\text { Certifying company } \\
\text { (e) }\end{array}$ & Low & $\begin{array}{l}\text { Low } \rightarrow \\
\text { Average }\end{array}$ & $\begin{array}{l}\text { Cannot force to implement EMS directly but can force indirectly } \\
\text { by not given certification. Advises how to improve environmental } \\
\text { performance. }\end{array}$ \\
\hline $\begin{array}{l}\text { A major customer } \\
\text { (p) }\end{array}$ & - & Low & $\begin{array}{l}\text { Recommendations and experiences concerning a specific perfor- } \\
\text { mance management system. }\end{array}$ \\
\hline
\end{tabular}

As we found that the actors had different roles in implementing EMS and PMS. For instance CEOs promoted and tried to show the importance of construction and utilization of management systems. On the other hand, quality manager and technical director implemented practically the different management systems. Table 3 summarizes these roles of the internal and external actors. 
Table 3 Different participants and their roles in management systems implementation

\begin{tabular}{|l|l|}
\hline Participant of the group & Role \\
\hline Internal actors & $\begin{array}{l}\text { Cost/benefit analysis of projects; PR concerning environ- } \\
\text { mental management system }\end{array}$ \\
\hline CEOs & $\begin{array}{l}\text { Motivation of PMS usage in a steering committee of the } \\
\text { largest subsidiary and group }\end{array}$ \\
\hline CEO of the largest subsidiary & $\begin{array}{l}\text { To push construction of worthwhile measures, teaching of } \\
\text { users, link between IT department and software vendor. }\end{array}$ \\
\hline Controller & Catalyst for renewing information systems \\
\hline IT director & Promotion and implementation of EMS \\
\hline Quality manager & $\begin{array}{l}\text { The promotion of technological innovations which help to } \\
\text { achieve environmental targets }\end{array}$ \\
\hline Technical director & Updating of measures \\
\hline Unit managers & \multicolumn{2}{|l|}{$\begin{array}{l}\text { The setting the lowest level of environmental indicators. } \\
\text { Questions concerning environmental performance }\end{array}$} \\
\hline External actors & $\begin{array}{l}\text { From certifier to external advisor/consultant how to im- } \\
\text { prove environmental performance and management }\end{array}$ \\
\hline ties & Illustrator how PMS was implemented \\
\hline Certifying company &
\end{tabular}

\section{Discussion}

This study investigated the implementation of EMS and PMS in a case company. We learned that the implementations of these systems had several differences although they were finally integrated into one greener PMS. First, the EMS and PMS implementation had both internal and external actors and the number of actors was higher in PMS than EMS implementation. Second, the case company had more external actors of organization when they implemented EMS than PMS. However, these external actors did not have high status or power in EMS implementation. The similarities were also found in implementation of EMS and PMS. Third, the both implementations had actors from different levels of organization and with different level of power and status. Finally, the both EMS and PMS implementations strengthened the measurement culture in a company.

We found that the case company had several different actors when they were implementing EMS and PMS. However, some of their interests were homogeneous when they all tried to improve the financial performance and the existing management systems. All the participants are operating in a same company which might be one main reason for this homogeneity of interests. On the other hand, the actors had also their own individual interests and agendas in EMS and PMS implementation. For instance Quality manager and Technical director wanted to improve the utilization of environmental measures in plants, environmental certifier requested environmental measures, IT direc- 
tor wanted to centralize fragmented management systems and Controller tried to implement an utilizable PMS. The final solution, greener PMS was developed as a collective action of these actors and as a synthesis of these agendas.

Therefore, our study has both similarities and differences with Markus et al. (2006). Our results are similar with Markus et al. (2006) because we both found heterogeneity of interests. Our results differ from Markus et al. (2006) because we found also homogeneity of actors' interest. The differences between studies are not surprising because Markus et al. (2006) had participants from several different organizations in one industry. However, we had also multiple actors in inter-organizational field who involved for constructing EMS and PMS in a case company (cf. Hargrave and Van de Ven, 2006). These actors represented different levels, companies and functions of a group as well as a major customer and environmental authorities.

We describe the theoretical contribution relating collective action theory and management accounting at the next. We also provide managerial implications and present the limitations of the study.

\section{Theoretical contribution; Collective action theory}

This study focused the concept of collective action theory which is derived from management and organizational studies. However, there are also a large number of different studies in economics which has used also the concept of collective action (e.g. Myatt and Wallace, 2009).

According to our results, we suggest that the utilized framework of Gibson and Earley (2007) may be developed. First, the actor part of framework may include both power and status characteristics of the actors. We found that these two characteristics differed in our study and that these differences are important. This means that both power and status should be considered separately as different concepts and not together in analysis (Lovaglia et al., 2003). This kind of separation enabled to analyze if the power and status of the actor differs or if some changes occurs in status or power of the actor. Secondly, it would be beneficial to add into the framework of Gibson and Earley (2007) both the individual and common interests of actors (see for instance Markus et al. 2006). As we found, some of the interests in EMS and PMS implementation projects can be homogenous (such as the improvement of financial performance) for all actors whereas some interests are specific for individual actors.

This study reveals the importance the separation between power and status and thus confirms the classification of Lovaglia et al. (2003). This separation has not been performed in several earlier studies which apply collective action (See for instance Gibson and Earley 2007, Hargrave and Van 
de Ven, 2006; Tang 2008) or institutional theory (See for instance Burns and Scapens, 2000; Pihlanto, 2000; Granlund, 2001; Kasurinen, 2002; Lukka, 2007) although the actors and their roles has been considered to be important in implementation of new systems also in this study. We found that the levels of power and status differed between the actors of the EMS and PMS implementation processes. We also found that high power does not result also high status in EMS and PMS implementation groups. The relation between power and status was also opposite among some actors, i.e. actor may have high status although the actor does not have high power.

On the other hand, we clearly found that the status of actor in EMS and PMS implementation differed. The status of actor can change although the power can be static during implementation which is not emphasized in earlier studies (see for instance Lovaglia et al., 2003). Therefore, this study confirms Flanagin et al. (2006) proposition that actors' mode of interaction and engagement can change over time. However, Flanagin et al. (2006) study does not focus on a single case company and its actors and thus our study contributes their study. On the other hand, this study confirms -in the context of EMS and PMS implementation process - the results of Jarzabkowski and Searle (2004) that high team diversity is important in collective action. This diversity enabled to implement a greener PMS when there were both actors who implemented the system in practice as well actors who revealed the necessity of the system. Our results show that this diversity is important also in other teams than only top-management team which is an extension to the study of Jarzabkowski and Searle (2004).

The roles can change during the implementation of EMS and PMS which was observed with CEO and environmental certifier. Therefore, we conclude that the roles are not static and different participants may have more important role in the earlier or later stages of the implementation project. We found that, for instance, the CEO of the group had more important role in the beginning of the EMS project and CEO's role changed during the course of implementation process. Therefore, CEO used power to legitimize the need for change of current management systems (Hargrave and Van de Ven, 2006) in the beginning of the project, eventough it was left to other peoples job to complete the project. On the other hand, the role of environmental certifier changed from a pure auditor to more practical advisor during the process. The changing role of accountants has been a popular theme in accounting studies in recent years (e.g. Nor-Aziah and Scapens, 2007; Ribeiro and Scapens, 2006; Järvenpää, 2007). We found that also the roles of other actors can change during the EMS and PMS implementation and this may affect the implementation process. Therefore, this study contributes to the earlier collective action studies which do not explicitly notify that status can be changing during implementation (see for instance Gibson and Earley, 2007). In addition to collective action theory 
studies, the other well-developed change models do not investigate explicitly the role of actors and their changing status (Kasurinen, 2002, Lounsbury, 2008).

This study has theoretical contribution compared to earlier collective action theory studies. First, it proposes that power and status are two separate important factors which affect group performance (cf. Gibson and Earley, 2007). This means that it may be useful for the collective action studies to investigate these two factors separately in the future. Secondly, the status of an actor can change during the course of the implementation process (Lovaglia et al., 2003) of the EMS and PMS. Depending on the actor, the status can increase or decrease. Lovaglia et al. (2003) proposes that the status attainment has value to individuals in terms of rewards, increased resources and power. Thirdly, we have qualitative empirical case data to analyze the EMS and PMS implementation processes. Several earlier collective action studies have proposed different models without this kind of rich empirical real life data (cf. Gibson and Earley, 2007; Lovaglia et al., 2003; Tang 2008). This kind of investigation with empirical data is highly recommended also by Lounsbury (2008). Lounsbury (2008) explicitly proposes that "much more needs to be done where logics and new practices come from and how they relate to each other". Therefore, this study response to the recommendation of Lounsbury (2008), when it includes a rare empirical insight into to the convergence of an EMS and PMS in a real-world setting. Fourthly, this study focuses on a single case company instead of industrial level analysis (cf. Markus et al., 2006) or only a single company top management team (Jarzabkowski and Searle, 2004).

\section{Theoretical contribution; Management accounting change and environ- mental accounting}

We consider that our study contributes earlier change studies in management accounting. As we know, institutional theory has been popularly used for interpreting the change process in different management accounting or management accounting information system studies (e.g. Baxter and Chua, 2003; Granlund, 2001; Soin et al., 2002; Tsamenyi et al., 2006). In particular, Burns and Scapens (2000) institutional framework has been utilized in several different studies in recent decade (e.g. Guerreiro et al. 2006; Lukka, 2007; Nor-Aziah and Scapens, 2007; Soin et al., 2002). Despite the high utilization of framework of Burns and Scapens (2000), we did not consider interesting to utilize it in this study because their framework does not specifically investigate the role of different actors during the change process. To solve the challenge of Burns and Scapens (2000) framework, we decided to utilize both the frameworks of Gibson and Earley (2007) and Lovaglia et al. (2003). 
As this study revealed, the several different actors had different roles, status and power and all these actors had important impact on implementation of two systems. Furthermore, results presented that the status of some actors changed during the implementation of two different management systems. Therefore, this study confirms the results of earlier studies that the actors are important when companies are changing their PMS (see for instance Burns, 2000; Granlund, 2001; Nor-Aziah and Scapens, 2007). Therefore, we consider that it might be purposeful to include actors and their roles, status and power into the institutional theory framework of Burns and Scapens (2000) more specifically because these factors were so important in our study in the field of management systems implementation.

We consider that this study contributes also environmental accounting literature. This study is a response to the presented limitations of earlier environmental accounting studies by Adams and Larrinaga-González (2007) and Ball (2007). According to Adams and Larrinaga-González (2007), very little attention is paid on how organizational characteristics influence on environmental accounting in practice or how the impact of practice of environmental accounting affects on organizations and their participants. Also Ball (2007) recommended to investigate "the ideological commitment of ... private sector managers and accountants in relation to the environmental agenda". Therefore, this paper clearly found that the importance of different actors, when different organizations are implementing different management systems like EMS and PMS in practice. Furthermore, the study showed the importance of consideration of organizational culture, like profit-oriented and measurement culture in this study, when implementing different management systems (Adams and Larrinaga-González, 2007). The profit oriented culture may affect for instance the selection of suitable environmental measures (see for instance Länsiluoto and Järvenpää, 2008).

\section{Managerial implications}

We consider that this study has also managerial implications. First, it is important to select the key actors in EMS and PMS implementation deliberately and carefully in the beginning of the process. Second, the high power of an actor does not mean directly the high status of the actor in implementation of management control systems. Thirdly, it might be purposeful to consider if the actors' status is beneficial to change during long-lasting implementation projects. The CEO may have high status in implementation at the beginning stage e.g. in the motivation and the status of CEO may decrease during the later and more detailed stages of the implementation process. On the other hand, for instance controller's status can be a low in the beginning and the status may increase during the course of implementation. Fourthly, the implementation of management systems may have 
both internal and external actors of organization, and it is also useful to take the external impact into account during the process. The internal actors can practically implement different systems whereas external actors can bring their experience as well recommendations how the systems could be implemented. The actors of implementation can differ between EMS and PMS although these systems would be integrated in the end. Fifthly, the actors may have both individual and common interests in implementation. Therefore, it is important to ensure that these interests are not conflicting (see for instance Markus et al. 2006) in a counterproductive way that could jeopardize the success of the project. Sixthly, collective action is required in this kind of demanding implementation projects if the goal is clearly defined, i.e. the implementation of EMS and PMS in this study. On the other hand, the adjustment of collective action may cause many practical challenges during the process. Finally, the organizational culture needs to be considered as one important factor which affects the implementation on EMS and PMS systems in practice (Adams and Larrinaga-González, 2007; Länsiluoto and Järvenpää, 2008).

\section{Limitations and new research directions}

This study has its limitations which can be considered in future studies. The first limitation relates to the methodology utilized. Due to the use of qualitative case methodology, the results can be generalized only in a theoretical or contextual way (Enquist et al., 2006; Lukka and Kasanen, 1995). Therefore, we believe, that even companies with moderate similarities, like firms in a food industry, with a similar culture or with a similarly fragmented IS can learn from this study. In the future, our foundations could be enlarged through field study methods including several case sites or statistically tested by analyzing wide survey data. The second limitation may relate to the number of interviewed representatives, which was only ten. However, both researchers participated in all interviews, and as a result, we consider that we were able to get richer data than if we had used only one interviewer. Moreover, the researchers felt that they had interviewed all the important managers whose views were really relevant to this particular research question, and that further enquiries would not have revealed any more useful information. The third limitation relates to the datagathering period when the data was gathered after the implementation. On the other hand, the construction of an EMS preceded the PMS and consequently the interviewees might have remembered the issues relating to PMS topics better. We diminished the effect of this weakness by conducting several different interviews and through the triangulation. The fourth limitation may relate to the described levels of status and power between the actors. These levels are based rather on researchers' subjective interpretation than any specific measure of the level. However, both researchers concluded the similar levels of actors. The last limitation may relate to used collective action theory 
which has been utilized in the industry-wide settings (see for instance Markus et al., 2006). However, we consider that the last limitation is actually the strength of the study when we focus on an implementation of two management systems in a single case company where the status and power of actors differ (see for instance Jarzabkowski and Searle, 2004; Lovaglia et al., 2003). Therefore, this study focuses rather on actors in a single company than social movement. If we are interested more on social movement, then we should investigate also external changes in the wider society and culture in more detail (Ball, 2007; Hargrave and Van de Ven, 2006).

Despite the limitations, this study brought perhaps more new research questions than answers. These questions can be analyzed in the future studies. First, the motivations of the actors need more examinations. It could for example be investigated if some participants were active in implementation of EMS and PMS because they wanted to improve or remain their status in the organization. For instance, Lovaglia et al. (2003) propose in their conceptual study that status attainment may be an incentive which motivates public goods contribution. Secondly, it could be interesting to investigate also how the wider changes in society and culture affect the different actors and their power and status in implementing different management systems such as EMS in private sector. Earlier studies have proposed that external changes such as cultural and social changes may affect the implementation of different systems (e.g. Ball, 2007; Hargrave and Van de Ven, 2006; Länsiluoto and Järvenpää, 2008) Finally, the usage of ANT would provide an opportunity to study also the roles of non-human actors in EMS and PMS implementation processes.

\section{Conclusions}

This study contributes both to the studies in collective action theory, the implementation of EMS and PMS literature and earlier management accounting studies. Collective action theory is contributed when we illustrated how the frameworks of Gibson and Earley (2007) and Lovaglia et al. (2003) can be utilized in practice. We also found that the power and status of actor are different concepts and they should be considered rather separately than together. Furthermore, the status is rather dynamic than static concept and the status of actor can change during the implementation of different management control systems like EMS and PMS. This kind of status change may be beneficial, because different competences may be required in different stages of the implementation projects.

In addition to contribution concerning collective action theory, this study contributes earlier management accounting studies. The contribution relates these studies which have utilized the institutional theory framework of Burns and Scapens (2000). Our study proposes that it might be purpose- 
ful to include actors and their roles, status and power into the institutional theory framework of Burns and Scapens (2000) more specifically. Therefore, we found that these characteristics of actors have a large effect on the performance of group and subsequently the implementation of different management systems.

We consider that our study contributes also the EMS and PMS integration studies. Earlier integration studies have been usually normative without empirical investigation (Figge et al., 2002; Hubbard, 2008; Chung and Parker, 2008; Yongvanich and Guthrie, 2006). This study illustrates who were the actors in implementing EMS and PMS, how these actors contributed to the implementation as a collective action and how these two management systems were finally integrated into one greener PMS.

\section{Acknowledgements}

The authors appreciate the interviewed managers in the case company for their positive attitude concerning this research project. The financial support of the Finnish Foundation for Economic Education (application number 26716) is also greatly acknowledged. Finally, we thank the anonymous reviewers of the paper and their constructive comments which improved the quality of the paper. 


\section{References}

Adams, C. A. and Larrinaga-González, C. (2007), "Engaging with organisations in pursuit of improved sustainability accounting and performance", Accounting, Auditing and Accountability Journal, Vol. 20 No. 3, pp. 333-355.

Ahrens, T. and Chapman, C. (2006), "Doing qualitative field research in management accounting: Positioning data to contributing the theory", Accounting, Organizations and Society, Vol. 31, pp. 819-84.

Ahrens, T. and Dent, J.F. (1998), “Accounting and Organizations: Realizing the Richness of Field Research”, Journal of Management Accounting Research, Vol. 10, pp. 1-39.

Baxter, J. and Chua, W.F. (2003), "Alternative management accounting research-whence and whither", Accounting, Organizations and Society, Vol. 28 Iss. 2-3, pp. 97-126.

Alcouffe, S., Berland, N. and Levant, Y. (2008), "Actor-networks and the diffusion of management accounting innovations: A comparative study", Management Accounting Research, Vol. 19 No. 1, pp. 1-17.

Ball, A. (2007), "Environmental accounting as workplace activism", Critical Perspectives on Accounting, Vol. 18 Iss. 7, pp. 759-778.

Baxter, J. and Chua, W.F. (2003), "Alternative management accounting research-whence and whither", Accounting, Organizations and Society, Vol. 28, Iss. 2-3, pp. 97-126.

Bourguignon, A., Malleret, V. and Nørreklit H. (2004), “The American balanced scorecard versus the French tableau de bord: the ideological dimension", Management Accounting Research, Vol. 15 Iss. 2, pp. 107-134.

Burns, J. (2000), “The dynamics of accounting change Inter-play between new practices, routines, institutions, power and politics", Accounting, Auditing and Accountability Journal, Vol. 13 Iss. 5, pp. 566-596.

Burns, J. and Scapens, R.W. (2000), “Conceptualizing management accounting change: an institutional framework", Management Accounting Research, Vol. 11, pp. 3-25.

Callon, M. (1998), "Actor-network theory, the market test", in Law, J. and Hassard, J., (eds.), Actor Network Theory and after, Blackwell Publishing, pp.181-195.

Carroll, G.R. and Hannan, M.T. (1989), Density Dependence in the Evolution of Populations of Newspaper Organizations. American Sociological Review, 54: 524-548. 
Chou, T-Z, Chen, J-R. and Pu, C.-K. (2008), "Exploring the collective actions of public servants in e-government development”, Decision Support Systems, Vol. 45 Iss. 2, pp. 251-265.

Chung, L.H. and Parker, L.D. (2008), "Integrating hotel environmental strategies with management control: a structuration approach", Business Strategy and the Environment, Vol. 17 No. 4, pp. 272286.

Darnall, N. (2006), "Why Firms Mandate ISO 14001 Certification”, Business and Society, Vol. 45 Iss. 3, pp. 354-381.

Dias-Sardinha, I. and Reijnders, L. (2005), "Evaluating environmental and social performance of large Portuguese companies: a balanced scorecard approach", Business Strategy and the Environment, Vol. 14 No. 2, pp. 73-91.

DiMaggio, P., Powell, W. (1983), “The Iron Cage Revisited: Institutional Isomorphism and Collective Rationality in Organizational Fields“, American Sociological Review, Vol. 48, April, pp. 147160.

Enquist, B., Johnson, M. and Skålén P. (2006), “Adoption of corporate social responsibility - incorpo-rating a stakeholder perspective", Qualitative Research in Accounting and Management, Vol. 3 No. 3, pp. 188-207.

Epstein, M.J. and Wisner, P.S. (2001), "Using a balanced scorecard to implement sustainability", Environmental Quality Management, Vol. 11 No. 2, pp. 1-10.

Figge, F., Hahn, T., Schaltegger, S. and Wagner, M. (2002), "The Sustainability Balanced Scorecard - linking sustainability management to business strategy", Business Strategy and the Environment, Vol. 11 No. 5, pp. 269-284.

Flanagin, A.J., Stohl, C. and Bimber, B. (2006), "Modeling the Structure of Collective Action", Communication Monographs, Vol. 73 No. 1, pp. 29-54.

Garud, R., Jain, S., \& Kumaraswamy, A. (2002), "Institutional entrepreneurship in the sponsorship of common technological standards: The case of Sun Microsystems and Java", Academy of Management Journal, Vol. 45, pp. 196-214.

Gibson, C.B. and Earley, P.C. (2007), "Collective cognition in action: accumulation, interaction, examination and accommodation in the development and operation of group efficacy beliefs in the workplace", Academy of Management Review, Vol. 32 No. 2, pp. 438-458.

Granlund, M. (2001), "Towards explaining stability in and around management accounting systems", Management Accounting Research, Vol. 12, pp. 141-166. 
Guerreiro, R., Pereira, C.A. and Frezatti, F. (2006), "Evaluating management accounting change according to the institutional theory approach: A case study of a Brazilian bank", Journal of Accounting \& Organizational Change, Vol. 2 Iss. 3, pp. 196-228.

GRI, Global reporting initiative (2008), Sustainability Reporting Guidelines, http://www.globalreporting.org/NR/rdonlyres/ED9E9B36-AB54-4DE1-BFF2-

5F735235CA44/0/G3_GuidelinesENU.pdf (downloaded October 22, 2008)

Hargrave, T.J. and Van de Ven, A.H. (2006), "A collective action model of institutional innovation”, Academy of Management Review, Vol. 31 No. 4, pp. 864-888.

Hubbard, G. (2008),"Measuring organizational performance: beyond the triple bottom line", Business Strategy and the Environment, DOI: 10.1002/bse.564, In press available http://www3.interscience.wiley.com/cgi-bin/fulltext/113518348/PDFSTART

Hyvönen, T., Järvinen, J. and Pellinen, J. (2008), “A virtual integration - The management control system in a multinational enterprise”, Management Accounting Research, Vol. 19 No. 1, pp. 45-61.

Jacobs, B. and Suckling, S. (2007), “Assessing customer focus using the EFQM Excellence Model: a local government case”, The TQM Magazine, Vol. 19 No. 4, pp. 368-378.

Jarzabkowski, P. and Searle, R.H. (2004), "Harnessing Diversity and Collective Action in the Top Management Team”, Long Range Planning, Vol. 37 No. 5, pp. 399-419.

Järvenpää, M. (2007), Making business partners: A case study on how management accounting culture was changed, European Accounting Review, Vol. 16, 1, 99-142.

Kaplan, R.S. and Norton, D.R. (2005), “The Balanced Scorecard: Measures That Drive Performance (cover story)", Harvard Business Review, Vol. 83 No. 7/8, pp. 172-180.

Kasurinen, T. (2002), "Exploring management accounting change: The case of balanced scorecard implementation", Management Accounting Research, Vol. 13 No. 3, pp. 323-343.

Lee, B. and Humphrey, C. (2006), "More than a numbers game: qualitative research in accounting", Management Decision, Vol. 44 No. 2, pp. 180-197.

Lounsbury, M. (2008), "Institutional rationality and practice variation: New directions in the institutional analysis of practice", Accounting, Organizations and Society, Vol. 33, Iss. 4-5, pp.349-361.

Lovaglia, M.J, Willer, R. and Troyer, L. (2003), "Power, status and collective action: developing fundamental theories to address a substantive problem", Advances in Group Processes, Vol. 20, pp. 105-131. 
Lozano, M. and Vallés, J. (2007), “An analysis of the implementation of an environmental management system in a local public administration", Journal of Environmental Management, Vol. 82 No. 4, pp. 495-511.

Lukka, K. (2007), "Management accounting change and stability: Loosely coupled rules and routines in action”, Management Accounting Research, Vol. 18 No. 1, pp. 76-101.

Lukka, K. and Kasanen, E. (1995), "Methodological themes: The problem of generalizability: Anecdotes and evidence in accounting research", Accounting, Auditing and Accountability Journal, Vol. 8 No. 5, pp. 71-90.

Länsiluoto, A. and Järvenpää, M. (2008), "Environmental and performance management forces: Integrating "greenness" into balanced scorecard", Qualitative Research in Accounting \& Management, Vol. 5 No. 3, pp. 184-206.

Magrini, A. and Lins, L.S. (2007) "Integration between environmental management and strategic planning in the oil and gas sector", Energy Policy, Vol. 35 No. 10, pp. 4869-4878.

Malmi, T. (2001), "Balanced scorecards in Finnish companies: A research note", Management Accounting Research, Vol.12 No. 2, pp. 207-220.

Markus, M., Steinfield, C. , Wigand, R. and Minton, G. (2006), "Industry-wide information systems standardization as collective action: the case of the U.S. residential mortgage industry", MIS Quarterly, Vol. 30, Special issue, pp. 439-465.

Meyer, R. (1977), "Institutionalized Organizations: Formal Structures as Myths and Ceremony", American Journal of Sociology, Vol. 83, pp. 340-363.

Melnyk, S.A, Srouf, R.P and Calantone, R. (2003), "Assessing the impact of environmental management systems on corporate and environmental performance", Journal of Operations Management, Vol. 21 No. 3, pp. 329-351.

Modell S. (2005), "Triangulation between case study and survey methods in management accounting research: An assessment of validity implications", Management Accounting Research, Vol. 16 No. 2, pp. 231-254.

Murdoch, A. (1997), “The performance pyramid”, Accountancy, London, Vol. 120 No. 1252, p. 52. Nor-Aziah, A.K. and Scapens, R.W. (2007), "Corporatisation and accounting change: The role of accounting and accountants in a Malaysian public utility”, Management Accounting Research, Vol. 18 No. 2, pp. 209-247. 
Myatt, D.P and Wallace, C. (2009) Evolution, Teamwork and Collective Action: Production Targets in the Private Provision of Public Goods, The Economic Journal, Vol. 119 No. 534, pp. 61-90. Neely, A., Adams, C. and Kennerly, M. (2002) The Performance Prism. The Scorecard for Measuring and Managing Business Success. Prentice Hall, London.

O'Connor, N.G. and Feng, E. (2005), "Using the balanced scorecard to manage intangible assets in a sino-foreign joint venture", Australian Accounting Review, Vol. 15 No. 2, pp. 22-29.

Pedersen, E.R. and Neergaard, P. (2008), "From periphery to center: how CSR is integrated in mainstream performance management frameworks", Measuring Business Excellence, Vol. 12 No. 1, pp. 4-12.

Pihlanto, P. (2000), Institutionaalinen teoria ja yksilötaso. Havaintoja Burnsin \& Scapensin viitekehyksen pohjalta, (Institutional Theory and the Level of an Individual. Reflections on the Burns \& Scapens Framework), Publications of the Turku School of Economics and Business Administration, Vol. 9.:2000.

Rao, H., Monin, P. and Durand, R. (2003), "Institutional change in toque ville: Nouvelle cuisine as an identity movement in French gastronomy", The American Journal of Sociology, Vol. 108, No. 4, pp. 795-843.

Ribeiro, J.A. and Scapens, R.W. (2006), "Institutional theories in management accounting change: contributions, issues and paths for development", Qualitative Research in Accounting and Management, Vol. 3 No. 2, pp. 94-111.

Scott, W. R. (2001), Institutions and Organizations, $2^{\text {nd }}$ ed. Sage, CA.

Soin, K., Seal, W. and Cullen, J. (2002), “ABC and organizational change: an institutional perspective”, Management Accounting Research, Vol. 13 No. 2, pp. 249-271.

Tang, L. (2008), “An Integral Model of Collective Action in Organizations and Beyond”, Journal of Business Ethics, Vol. 80 No. 2, pp. 249-261.

Tsamenyi, M., Cullen, J. and González, J.M. (2006), "Changes in accounting and financial information system in a Spanish electricity company: A new institutional theory analysis", Management Accounting Research, Vol. 17 No. 4, pp. 409-432.

Vogel, B. (2005), "Linking for Change: Network Action as Collective, Focused and Energetic behaviour", Long Range Planning, Vol. 38 No. 6, pp. 531-553. 
Wagner, M. (2007), “Integration of Environmental Management with Other Managerial Functions of the Firm: Empirical Effects on Drivers of Economic Performance", Long Range Planning, Vol. 40 No. 6, pp. 611-628.

Woodside, A.G. and Wilson, E.J (2003), "Case study research methods for theory building”, The Journal of Business \& Industrial Marketing, Vol. 18 No. 6/7, pp. 493-508.

Yongvanich, K. and Guthrie, J. (2006), “An extended performance reporting framework for social and environmental accounting", Business Strategy and the Environment, Vol. 15 No. 5, pp. 309321.

Interviews in a case company

1. Business area director of the largest subsidiary, member of executive board of the largest subsidiary. Interviewed August 29, 2006.

2. Business area director of the largest subsidiary, member of executive board of the largest subsidiary. Interviewed August 23, 2006.

3. Business unit manager of a larger production plant. Interviewed August 22, 2006.

4. Chief executive officer of group, member of board. Interviewed November 3, 2006.

5. Chief executive officer of the largest subsidiary, member of executive board of group, vice CEO of group. Interviewed December 8, 2006.

6. Controller of the largest subsidiary. Interviewed August 22, 2006.

7. Information technology and logistics (IT) director, member of group executive board. Interviewed September 1, 2006

8. Quality director, member of group executive board, business area director of the largest subsidiary. Interviewed August 24, 2006.

9. Quality manager of the largest subsidiary. Interviewed May 17, 2006 and August 29, 2006.

10. Technical director of the largest subsidiary, member of executive board of the largest subsidiary. Interviewed May 17, 2006 and September 25, 2006 